\title{
ADMINISTRAÇÃO PÚBLICA GERENCIAL: AS METAS DO CONSELHO NACIONAL DE JUSTIÇA
}

PUBLIC MANAGEMENT:

THE GOALS OF THE NATIONAL COUNCIL OF JUSTICE

Luiza Szczerbacki Castello Branco

Fundação Getúlio Vargas, Rio de Janeiro, RJ, Brasil. Email: luizascbranco@gmail.com

Recebido em: 30.12.2017 - Aceito em: 26.02.2018

DOI: http://dx.doi.org/10.5902/2526629230645

\section{RESUMO}

O Poder Judiciário brasileiro tem passado por uma crise de credibilidade frente à sociedade devido a sua morosidade. Assim, no ano de 2004, foi criado o Conselho Nacional de Justiça, que é o órgão competente pela administração desse Poder e que, por meio de um planejamento estratégico, estipulou metas de caráter obrigatório para todos os tribunais do país. Dessa forma, o presente estudo busca analisar a introdução do planejamento estratégico, técnica do setor privado, no setor público e, mais especificamente, no Poder Judiciário nacional. Os resultados demonstram que a simples introdução desse processo nos tribunais ocasionou o aumento da produtividade do Judiciário.

PALAVRAS-CHAVE: Conselho Nacional de Justiça; Metas; Planejamento Estratégico; Poder Judiciário.

\section{ABSTRACT}

The Brazilian judiciary has experienced a credibility crisis before society due to its slowness. Thus, in 2004 was created the National Council of Justice, the administrative body responsible for the administration of this Power and that through a strategic planning stipulated mandatory goal's for all courts of the country. Therefore, the present study investigates the introduction of strategic planning, a private sector technique, at the public sector and more specifically in the national Judiciary Power. The results show that the simple introduction of this process in the courts led to an increase of judicial productivity.

KEYWORDS: Goals; Judiciary Power; National Counsel of Justice; Strategic Planning. 


\section{INTRODUÇÃO}

O Poder Judiciário brasileiro tem passado por uma crise de credibilidade, sendo visto pela sociedade como sinônimo de lentidão e inoperância. A demanda por resolução de conflitos tem aumentado ano a ano sem que esse Poder modifique suas estruturas para acompanhar essa multiplicação, gerando um congestionamento de processos nos tribunais. Assim, a morosidade nos julgamentos, que não acompanharam a evolução da demanda social por justiça, acarretou no descrédito do Judiciário (Sadek, 2004a, 2004b; Grangeia, 2007; Bordasch, 2009; Deolindo, 2010).

Buscando solucionar tal problema, no ano de 2004, foi promulgada a Emenda Constitucional n 45, conhecida como "Reforma do Judiciário" (Cunha, 2010), que criou um órgão competente pelo controle da atuação administrativa e financeira do Poder Judiciário, qual seja, o Conselho Nacional de Justiça (CNJ). Desde então, vêm se observando, na gestão da Justiça brasileira, esforços voltados para a profissionalização e modernização de todos os tribunais do país, sob as diretivas desse Conselho (Jobim, 2005; Mendes, 2010).

Destarte, a prestação jurisdicional célere, eficiente e eficaz afigura-se como o alvo maior dos investimentos dessa Reforma Judiciária, que é extremamente complexa por abarcar mudanças tanto na seara jurídica como na administrativa e na legislativa (Fleury, 2005; Cunha, 2010). Entre os fenômenos a serem observados nos atuais esforços de transformação na gestão do Judiciário, tem-se a disseminação do planejamento estratégico. Este é tido como um processo de desenvolvimento de um plano de ações previamente traçado para o alcance de objetivos futuros (Taylor, 1975; Mintzberg, 1994; Mintzberg, Ahlstrand, \& Lampel, 2000; Motta, 2012). Nesse sentido, o planejamento estratégico do Poder Judiciário em nível nacional foi formalizado e divulgado no ano de 2009, por meio da Resolução do CNJ n 70 , estipulando metas de caráter obrigatório para todos os tribunais de justiça do país.

Assim, o presente trabalho visa analisar se a inserção do planejamento estratégico, técnica do setor privado, no Poder Judiciário Brasileiro, por meio das Metas Nacionais do CNJ, foi benéfico à Justiça pátria.

\section{REFORMA DO JUDICIÁRIO}

Assim como na década de 1990 houve a reforma do Estado no Brasil, a crise do Judiciário gerou um consenso neste Poder em relação à necessidade de uma reforma do sistema brasileiro de prestação jurisdicional (Tesheiner, 2001; Sadek, 2004a, 2004b). Nesse sentido, para diversos autores, uma das medidas 
mais importantes e desafiadoras seria a instituição de modelos gerenciais com vistas a aperfeiçoar a gestão administrativa da estrutura judicial de forma a se produzir mais e melhor com os recursos disponíveis (Sadek, 2004a, 2004b; Belchior, 1999; Grangeia, 2007; Deolindo, 2010). O resultado foi a promulgação da Emenda Constitucional $n^{\circ} 45$, em 8 de dezembro de 2004, conhecida como "Reforma do Judiciário" (Cunha, 2010), que, entre outras medidas, assegurou à sociedade, nos âmbitos judicial e administrativo, a razoável duração do processo (CRFB/88, art. $5^{\circ}$, LXXXVIII). Tal diretriz tem por finalidade dar maior celeridade aos julgamentos, perfilando-se ao princípio da eficiência na administração pública (CRFB/88, art. 37, caput), além de mirar na profissionalização da gestão da justiça (Kern, 2011).

A administração judiciária contemporânea precisa, então, entre outras medidas, alinhar-se com os ditames da eficiência da administração pública e do direito fundamental à razoável duração do processo. Para tanto, urge se empreender uma análise do planejamento estratégico como meio indispensável para a consecução da missão do Poder Judiciário, que é a de distribuir justiça efetiva, solucionando conflitos em tempo razoável (Koury, 2010; Kern, 2011).

Outra importante inovação da Emenda Constitucional n ${ }^{\circ} 45$ do ano de 2004 foi a criação do Conselho Nacional de Justiça (CRFB/88, art. 103-B) como órgão competente pela administração do Poder Judiciário, implementador de um novo modelo de gestão e indutor do planejamento estratégico em nível nacional (Koury, 2010). O CNJ passa, portanto, a ter o papel de órgão estratégico central daquele Poder. Suas ações impõem mudanças nos rumos do Judiciário, sobretudo diante da fixação de metas nacionais (Kern, 2011).

\section{PLANEJAMENTO ESTRATÉGICO}

O planejamento sempre foi uma das funções básicas da administração. Tanto assim que um dos quatro princípios da administração científica de Taylor (1975) era o planejamento (os demais eram: seleção ou preparo, controle e execução). Nessa mesma época, o francês Henry Fayol estabeleceu como primeira função do gestor a de previsão, ou seja, visualizar o futuro desenvolvendo um plano de ações para atingir as metas traçadas (Fleury, 2005).

O setor privado, necessitando acompanhar as rápidas alterações trazidas pela modernização da sociedade e pela concorrência cada vez mais acentuada dos mercados, a partir da metade dos anos 60 , transpôs para suas organizações os conceitos básicos da metodologia do planejamento estratégico, mediante as proposições do professor Igor Ansoff (Taylor, 1975; Mintzberg, 1994). 
Segundo o próprio Ansoff (1969), o planejamento estratégico consiste em uma série de diretrizes administrativas que especificam a posição da organização no mercado, as direções nas quais ela procura desenvolver-se e os instrumentos competitivos que ela empregará. É um processo contínuo de aprendizado, com maior conhecimento possível do futuro capaz de estimar o resultado de decisões de risco adotadas em confronto com as expectativas alimentadas (Drucker, 1984).

É através do exercício de planejar que se aprende sobre as demandas e necessidades externas e sobre a capacidade de resposta da empresa. Mesmo quando não implementados, os planos revelam as expectativas e referências de valor, essenciais a um grupo de trabalho (Motta, 2012). O planejamento estratégico tem por objetivo, portanto, posicionar, de forma competitiva, a organização em seu ambiente, fornecendo a direção que se deve seguir, sendo crucial para o sucesso em longo prazo de toda instituição (Marcovitch \& Vasconcelos, 1977; Marcovitch \& Radosevich, 1978).

\section{PLANEJAMENTO ESTRATÉGICO NO SETOR PÚBLICO}

Diversas foram as organizações privadas que adotaram o processo de planejamento no mundo inteiro. Muitas delas, porque bem feita a sua formulação, execução e controle, alcançaram resultados positivos, sendo, portanto, crucial para o sucesso da instituição (Herold, 1972; Marcovitch \& Radosevich, 1978; Marin, 2012). No mais, o planejamento estratégico, além dos avanços metodológicos, significa a conquista da visão de grande escopo na determinação dos propósitos e caminhos organizacionais.

Do mesmo modo, devido às frequentes e rápidas mudanças no ambiente, além do contexto de transformações radicais da sociedade e do Estado, que se deram de forma acelerada nas últimas décadas, impôs-se, também, a modernização do setor público (Darós, 2009). Diversos autores (Osborne \& Gaebler, 1996; Peters \& Pierre, 1998; Milward \& Provan, 2000) enfatizaram a necessidade de mudanças nos governos, tendo em vista as transformações que vêm se perpetrando enquanto aqueles continuam estáticos.

Com isso, a partir da década de 1990, no contexto das reformas dos órgãos do Estado brasileiro, sob o foco da administração gerencial, passou a ser relevante a capacidade de gerenciamento (Cavalcanti, 2005). A gestão na atividade pública passou a ser tão importante quanto no setor privado (Marin, 2012), caracterizando-se por uma despolitização da administração, aliada à ênfase no conceito de eficiência governamental (Fleury, 2005). 
A partir da década de 1980, o corpo de ideias conhecido como New Public Management (NPM) influenciou e incentivou reformas administrativas em diversos governos nacionais. Para Osborne \& Gaebler (1996), por exemplo, o tipo de governo desenvolvido durante a Era Industrial, que era lento, com burocracias centralizadas, preocupado com normas e regulações, além de canais de comando hierárquico, não funciona mais. Os autores propõem, assim, que o governo poderia se apropriar do modelo de fornecimento de serviços do setor privado, como, por exemplo, a flexibilidade de gestão, o foco na qualidade dos serviços e a prioridade às demandas dos consumidores. Destarte, na gestão pública, a introdução do planejamento estratégico faz referência ao movimento do New Public Management (Shick, 1996), validando-o como referência para a tomada de decisões sobre como estruturar e gerir os serviços públicos (Barzelay, 2001).

A administração gerencial tem suas premissas voltadas para a eficiência, agilidade, qualidade e flexibilidade da gestão, além da preocupação com o aumento da responsabilização da administração pública (Campos, 1990; Dror, 1999; Abrucio, 2005; Cavalcanti, 2005; Abrucio \& Sano, 2008; Cunha, 2010), fortalecimento do gerenciamento público e imputação de resultados (Costin, 2010). Tais conceitos e práticas passam, então, a nortear o modelo gerencial público, direcionando a adaptação e a transferência dos conhecimentos desenvolvidos nas empresas para a seara pública (Peci, Pieranti, \& Rodrigues, 2008).

Em suma, prevalecia a ideia de maior eficiência das organizações privadas que necessitavam se desenvolver intensamente para sobreviver no ambiente competitivo. Considerando que em toda gestão, privada ou pública, existem desafios semelhantes, as técnicas e os conceitos que auxiliaram as empresas a se tornar ágeis e eficientes poderiam, então, ser utilizadas também no setor público (Frederickson, 1989; Osborne \& Gaebler, 1996).

Todavia, a NPM recebeu muitas críticas, entre as quais se destacam a pretensão de se constituir em uma prática universal, aplicável às diversas realidades independentemente das especificidades de cada local; a supressão de valores como a cidadania, a equidade e o bem-estar público ao deslocar a atenção para conceitos mais restritos, como o de eficiência e produtividade; e a desconsideração das diferenças essenciais existentes entre a administração pública e privada (Diefenbach, 2009).

Apesar de as teorias e os conceitos de planejamento fornecerem algumas diretrizes gerais, as circunstâncias de cada organização (tanto públicas quanto privadas) são tão específicas que a administração precisa adaptar essas generalizações quando da aplicação do planejamento. A adoção de um processo prescri- 
tivo, sem a devida adequação para a realidade organizacional de cada instituição, pode corresponder a um desperdício de tempo e recursos (Marcovitch \& Radosevich, 1978). Afinal, as organizações governamentais, além de inseridas num sistema social complexo e conflitivo (Darós, 2009), têm por objetivo prover ou contratar por meio de serviços, em geral não lucrativos, funções obrigatórias que têm para com a população ou o governo (Marin, 2012).

Ademais, enquanto há um nível de generalidade na administração, algumas funções que parecem semelhantes, podem assumir significados bem diferentes no âmbito do público e do privado (Allison, 2002). O escopo do setor privado é promover transformações estratégicas na companhia em busca de lucratividade no mercado. A função do governo, por seu turno, é promover e proteger o interesse público (Appleby, 2002). Nesse setor, o mercado é substituído por influências políticas, poder limitado por leis, responsabilidade para com os contribuintes e um corpo próprio de regulações (Marin, 2012). Allison (2002) lista uma série de diferenças entre essas duas áreas citando diversos trabalhos, como, por exemplo, o papel da imprensa e da mídia (de Dunlop, 1979), fatores ambientais, sistema de carreira e medição de performance (de Neustadt, 1979), entre outros.

Por fim, o planejamento estratégico no setor público é a integração, em todos os níveis da organização, do contínuo processo de formulação, implementação e avaliação do futuro da instituição com um horizonte de tempo razoável para a obtenção dos resultados pretendidos.

\section{PLANEJAMENTO ESTRATÉGICO NO PODER JUDICIÁRIO}

Na seara judiciária, o planejamento configura-se como a primeira função administrativa, por servir de base para as demais. Ele determina o que deve ser feito, os objetivos a serem alcançados, quais controles serão adotados e que tipo de gerenciamento será necessário para a obtenção de resultados satisfatórios (Grangeia, 2007).

A reflexão mais intensa sobre a necessidade do fortalecimento da gestão do Poder Judiciário só ganhou corpo, contudo, a partir da Constituição da República Federativa do Brasil de 1988, que reascendeu a demanda por modernização, transparência, prestação jurisdicional com qualidade e eficiência nas relações com a sociedade (Jobim, 2004).

Nos anos 90, o Judiciário começou a perceber que não era mais possível atender à demanda da sociedade com o modelo amador de gestão que possuía. Não obstante sua função precípua ser julgar, nos dias atuais é preciso que o julgamento se faça de modo eficiente, com resultados efetivos e em tempo socialmen- 
te justo. Compreendeu-se, então, que a gestão precisava ser profissionalizada (Leme, 2010). Com isso, a reflexão sobre estruturas e processos de gestão para o Judiciário implicou adaptar novos conceitos, ideias e práticas à natureza e às peculiaridades do papel da justiça nas relações sociais (Cunha, 2010).

Desse modo, em 1995, sob a influência da New Public Management (NPM), ocorreu a Reforma Gerencial do Estado Brasileiro, com a perspectiva de que os recursos públicos fossem utilizados com mais eficiência pelo Estado (Bresser-Pereira, 1997, 2000). Ademais, as proposições fundamentais da NPM estão ligadas à adoção de novos caminhos, tais como atividade orientada por missões explicitamente definidas; efetividade, eficácia e eficiência na prestação dos serviços; e envolvimento da sociedade e dos quadros internos na formulação e implementação de uma visão de futuro (Fleury, 2005). Como consequência, no início do ano 2000, intensificaram-se novamente os debates e a mobilização para a modernização das instituições judiciárias no país (Cunha, 2010).

Finalmente, com a promulgação da Emenda Constitucional $n^{\circ} 45$, do ano de 2004, e a consequente criação do Conselho Nacional de Justiça, observam-se esforços na gestão judicial para se profissionalizar e modernizar. Desde então, bons resultados vêm sendo obtidos por meio de ações de planejamento estratégico, estabelecimento de metas, indicadores de desempenho e produção de estatísticas (Campos, 2010). No ano de 2009, sob a presidência do ministro Gilmar Mendes, o CNJ aprovou a Resolução $n^{\circ} 70$, estabelecendo o planejamento e a gestão estratégica nacional de longo prazo do Poder Judiciário. Essa mudança de postura superou o modelo de descontinuidade bienal, na qual as políticas adotadas por uma administração eram descontinuadas pela seguinte', desenvolvendo a ideia de continuidade administrativa (Mendes, 2010).

Destarte, a gestão passou a ser algo primordial para que os juízes, responsáveis pela administração do Judiciário, pudessem continuar a julgar bem, com rapidez e eficiência diante da imensa demanda que se apresentava (Stumpf, 2009). No mais, o CNJ, como órgão definidor de políticas gerais de gestão e de controle, tem desempenhado um papel relevante para uniformizar a atuação gerencial dos tribunais do país, que sempre foi muito desigual (Leme, 2010). Entre o final do ano de 2009 e o início de 2010, a estratégia do Poder Judiciário nacional foi desdobrada para praticamente todas as suas instâncias em todos os segmentos da Justiça (Manzini, 2010). Para o ministro Gilmar Mendes (2010), a reforma do Judiciário é uma parte importante da reforma do Estado brasileiro na medida em que está mudando realidades não elogiáveis do Brasil, como a ideia de patrimonialismo.

1 Os mandatos dos presidentes dos Tribunais de Justiça do país são bienais, destarte a cada dois anos é eleita uma nova administração para o Tribunal. 


\section{A MENSURAÇÃO DAS METAS NACIONAIS DO CNJ}

Mensurar resultados é uma alternativa para responder às demandas crescentes de accountability, tanto políticas - referentes ao alinhamento entre as metas estabelecidas e os serviços prestados -, como sociais - referentes às exigências da opinião pública quanto à transparência e eficiência no uso de recursos públicos. Como consequência, a accountability vem sendo entendida como a obrigação permanente de prestar contas sobre o uso de recursos públicos, os resultados alcançados e os critérios de decisão utilizados (Pacheco, 2004).

Para o constante aprimoramento da gestão do Judiciário e principalmente das metas instituídas anualmente pelo $\mathrm{CNJ}$, mostra-se necessária uma mensuração dos resultados que estão sendo obtidos e dos objetivos que estão sendo alcançados. Pensando nisso, a alta administração do Poder Judiciário, em especial o CNJ, começou a concretizar o projeto de indicadores de desempenho no ano de 2008 (Nogueira, 2010). Com a publicação da Resolução do CNJ n 70/2009, a ideia de medir o desempenho seguiu com a definição de indicadores estratégicos, que mensuram o alcance dos objetivos estratégicos comuns a todos os tribunais. A finalidade é que os indicadores apontados sivam de subsídios instrumentais para a avaliação dos tribunais, assim como referência para a criação de uma cultura de planejamento e gestão estratégica (CNJ, 2009c).

Em suma, os indicadores de desempenho do planejamento estratégico trazem direções para que as metas sejam cumpridas, além de operar com noções sobre o que se precisa atingir em determinado momento. Isso tem contribuído para que o Poder Judiciário possa contar com o uso dessas informações para processos decisórios, com uma padronização em sua política nacional de mensuração de desempenho e com o aprimoramento, sempre que possível, da prestação de seus serviços (CNJ, 2009b; Nogueira, 2010).

Assim, pela análise das metas instituídas e implementadas pelo Conselho Nacional de Justiça entre os anos de 2009 e 2016, conforme Tabelas 1 a 8, percebe-se o desenvolvimento na gestão administrativa judiciária, por exemplo, com: o gradativo desdobramento de metas para todos os tribunais (tribunais federais, estaduais e juizados especiais) e justiças especializadas do país (Justiça Eleitoral, Justiça do Trabalho e Justiça Militar)2; esforços de diminuição do acervo de processos antigos e pendentes de julgamento ${ }^{3}$; a inserção de práticas de gestão 2 A Meta 2 do ano de 2009 contava apenas com as Justiças Estadual e Federal; no ano de 2010, ou seja, apenas um ano depois de implementada, a referida Meta 2 passou a abranger também as Justiças do Trabalho, Eleitoral e Militar, de forma a abarcar todas as Justiças especializadas do país. A Meta 1 do ano de 2012 passou a abranger todos os tribunais do Brasil.

3 Analisando globalmente o cumprimento da Meta 2 ao longo dos anos, percebe-se que houve uma majoração do seu percentual: 46\% em 2009, 26,96\% em 2010 (quando inseridas as justiças especializadas), 100\% em 2011 (Meta 3), 100\% em 2012, 123,92\% em 2013, 96,96\% em 2014, 93,31\% em 2015 e 94,06\% em 2016. 
com vistas a diminuir os custos operacionais ${ }^{4}$; a qualificação e capacitação dos funcionários ${ }^{5}$; a implantação de sistemas informatizados integrados ${ }^{6}$; etc.

Tabela 1 - Metas nacionais do CNJ referentes ao ano de 2009

Meta

Descrição

Total de cumprimento

Desenvolver e/ou alinhar planejamento estratégico plurianual (mí-

Meta 1 nimo de cinco anos) aos objetivos estratégicos do Poder Judiciário, com aprovação no Tribunal Pleno ou Órgão Especial.

$100 \%$

(Justiça Federal e Estadual) Identificar os processos judiciais

Meta 2 mais antigos e adotar medidas concretas para o julgamento de todos os distribuídos até 31 de dezembro de 2005.

Meta 3 Informatizar todas as unidades judiciárias e integrá-las ao respectivo tribunal e à rede mundial de computadores (internet).

Meta 4 Informatizar e automatizar a distribuição de todos os processos e recursos.

Meta 5 Implantar sistema de gestão eletrônica da execução penal e mecanismo de acompanhamento eletrônico das prisões provisórias.

$100 \%$

Capacitar o administrador de cada unidade judiciária em ges-

Meta 6 tão de pessoas e de processos de trabalho, para imediata implantação de métodos de gerenciamento de rotinas.

Tornar acessíveis as informações processuais nos portais da

Meta 7 rede mundial de computadores (internet), com andamento atualizado e conteúdo das decisões de todos os processos, respeitado o segredo de justiça.

Cadastrar todos os magistrados como usuários dos sistemas

Meta 8 eletrônicos de acesso a informações sobre pessoas e bens e $\quad 100 \%$ de comunicação de ordens judiciais.

Meta 9 Implantar núcleo de controle interno.

Meta Implantar o processo eletrônico em parcela de suas unidades

10 judiciárias.

Fonte: elaborada pela autora com base nos relatórios fornecidos pelo CNJ.

4 Como, por exemplo, a Meta 4 de 2009, as Metas 6 e 10 de 2010 e a Meta 9 de 2011.

5 Como, por exemplo, a Meta 6 do ano de 2009, a Meta 8 do ano de 2010, a Meta 15 do ano de 2012 e a Meta 11 do ano de 2013.

6 Como, por exemplo, as Metas 3 e 5 do ano de 2009, a Meta 6 do ano de 2011 e a Meta 19 do ano de 2013. 
Tabela 2 - Metas nacionais do CNJ referentes ao ano de 2010

$\begin{array}{ccc}\text { Meta } & \text { Descrição } & \text { Total de } \\ \text { cumprimento }\end{array}$

Julgar quantidade igual à de processos de conhecimento dis-

Meta 1 tribuídos em 2010 e parcela do estoque, com acompanha-

$100 \%$ mento mensal.

(Justiça Federal, Estadual, do Trabalho, Eleitoral, Militar) Julgar todos os processos de conhecimento distribuídos (em $1^{\circ}$ grau,

Meta $22^{\circ}$ grau e tribunais superiores) até 31 de dezembro de 2006 e, quanto aos processos trabalhistas, eleitorais, militares e da competência do tribunal do Júri, até 31 de dezembro de 2007.

Reduzir em pelo menos $10 \%$ o acervo de processos na fase de cumprimento ou de execução e, em $20 \%$, o acervo de

Meta 3 execuções fiscais (referência: acervo em 31 de dezembro de 2009).

Meta 4 Lavrar e publicar todos os acórdãos em até 10 dias após a sessão de julgamento.

$64,44 \%$

Implantar método de gerenciamento de rotinas (gestão de

Meta 5 processos de trabalho) em pelo menos $50 \%$ das unidades

$86,66 \%$ judiciárias de $1^{\circ}$ grau.

Meta 6 Reduzir a pelo menos $2 \%$ o consumo per capita com energia, telefone, papel, água e combustível (ano de referência: 2009).

$100 \%$

Meta 7 Disponibilizar mensalmente a produtividade dos magistrados no portal do tribunal.

$94,44 \%$

Meta 8 Promover cursos de capacitação em administração judiciária, com no mínimo 40 horas, para 50\% dos magistrados.

Ampliar para 2 Mbps a velocidade dos links entre o tribunal

Meta 9 e 100\% das unidades judiciárias instaladas na capital e, no $100 \%$ mínimo, 20\% das unidades do interior.

Realizar, por meio eletrônico, 90\% das comunicações oficiais

Meta 10 entre os órgãos do Poder Judiciário. Criar unidade de gerenciamento de projetos nos tribunais para auxiliar a implantação da gestão estratégica.

Fonte: elaborada pela autora com base nos relatórios fornecidos pelo CNJ. 
Tabela 3 - Metas nacionais do CNJ referentes ao ano de 2011

\begin{tabular}{clc}
\hline Meta & \multicolumn{1}{c}{ Descrição } & $\begin{array}{c}\text { Total de } \\
\text { cumprimento }\end{array}$ \\
\hline Meta 1 & $\begin{array}{l}\text { Criar unidade de gerenciamento de projetos para auxiliar a } \\
\text { implantação da gestão estratégica. }\end{array}$ & $85,55 \%$ \\
\hline Meta 2 & $\begin{array}{l}\text { Implantar sistema de registro audiovisual de audiências em } \\
\text { pelo menos uma unidade judiciária de primeiro grau em } \\
\text { cada tribunal. }\end{array}$ & $79,36 \%$ \\
\hline Meta 3 & $\begin{array}{l}\text { Julgar quantidade igual à de processos de conhecimento } \\
\text { distribuídos em 2011 e parcela do estoque, com acompa- } \\
\text { nhamento mensal. }\end{array}$ & $100 \%$ \\
\hline
\end{tabular}

Implantar pelo menos um programa de esclarecimento ao

Meta 4 público sobre as funções, atividades e órgãos do Poder Ju- 98,88\% diciário em escolas ou quaisquer espaços públicos.

\begin{tabular}{clc}
\hline Meta 5 & (Justiça Trabalhista) Criar um núcleo de apoio de execução. & $91,66 \%$ \\
\hline Meta 6 & $\begin{array}{l}\text { Disponibilizar nos sites dos Tribunais Regionais Eleitorais } \\
\text { (TREs) até dezembro de 2011 o sistema de planejamento } \\
\text { integrado das eleições. }\end{array}$ & $100 \%$ \\
\hline Meta 7 & $\begin{array}{l}\text { Implantar e divulgar a "carta de serviços" da Justiça Elei- } \\
\text { toral em 100\% das unidades judiciárias de primeiro grau } \\
\text { (Zonas Eleitorais) em 2011. }\end{array}$ & $100 \%$ \\
\hline
\end{tabular}

(Justiça Militar) Implantar a gestão de processos em pelo

Meta 8 menos $50 \%$ das rotinas administrativas, visando à implementação do processo administrativo eletrônico.

(Justiça Federal) Implantar processo eletrônico judicial e

Meta 9 administrativo em $70 \%$ das unidades de $1^{\circ}$ e $2^{\circ}$ graus até $100 \%$ dezembro de 2011.

Fonte: elaborada pela autora com base nos relatórios fornecidos pelo CNJ. 
Tabela 4 - Metas nacionais do CNJ referentes ao ano de 2012

\begin{tabular}{|c|c|c|}
\hline Meta & Descrição & $\begin{array}{c}\text { Total de } \\
\text { cumprimento }\end{array}$ \\
\hline $\begin{array}{c}\text { Meta } \\
1\end{array}$ & $\begin{array}{l}\text { (Todos os tribunais) Julgar mais processos de conhecimento do } \\
\text { que os distribuídos em } 2012 .\end{array}$ & $26,66 \%$ \\
\hline $\begin{array}{c}\text { Meta } \\
2\end{array}$ & $\begin{array}{l}\text { Julgar, até } 31 \text { de dezembro de } 2012 \text {, pelo menos, } 80 \% \text { dos pro- } \\
\text { cessos distribuídos em } 2007 \text { no STJ. }\end{array}$ & $100 \%$ \\
\hline $\begin{array}{l}\text { Meta } \\
3\end{array}$ & $\begin{array}{l}\text { Tornar acessíveis as informações processuais nos portais da } \\
\text { rede mundial de computadores (internet), com andamento atu- } \\
\text { alizado e conteúdo das decisões dos processos, respeitando o } \\
\text { segredo de justiça. }\end{array}$ & $86,66 \%$ \\
\hline $\begin{array}{l}\text { Meta } \\
4\end{array}$ & $\begin{array}{l}\text { Constituir Núcleo de Cooperação Judiciária e instituir a figura do } \\
\text { juiz de cooperação. }\end{array}$ & $96,66 \%$ \\
\hline $\begin{array}{l}\text { Meta } \\
5\end{array}$ & $\begin{array}{l}\text { Implantar sistema eletrônico para consulta à tabela de custas e } \\
\text { emissão de guia de recolhimento. }\end{array}$ & $90 \%$ \\
\hline $\begin{array}{l}\text { Meta } \\
6\end{array}$ & $\begin{array}{l}\text { (Justiça Militar Estadual) Implantar sistema de videoconferência } \\
\text { em pelo menos uma unidade judiciária, para oitiva de testemu- } \\
\text { nhas, em cooperação com outros segmentos de justiça. }\end{array}$ & $33,33 \%$ \\
\hline $\begin{array}{l}\text { Meta } \\
7\end{array}$ & $\begin{array}{l}\text { (Justiça Militar Estadual) Implantar projeto piloto do processo ju- } \\
\text { dicial eletrônico em pelo menos uma unidade judiciária. }\end{array}$ & $0 \%$ \\
\hline $\begin{array}{c}\text { Meta } \\
8\end{array}$ & $\begin{array}{l}\text { (Justiça Militar Estadual) Implantar o processo eletrônico em } \\
\text { pelo menos cinco rotinas administrativas. }\end{array}$ & $33,33 \%$ \\
\hline $\begin{array}{c}\text { Meta } \\
9\end{array}$ & $\begin{array}{l}\text { (Justiça Militar Estadual) Implantar sistema de registro audiovisu- } \\
\text { al de audiências em } 100 \% \text { das unidades judiciárias de } 1^{\circ} \mathrm{Grau} \text {. }\end{array}$ & $66,66 \%$ \\
\hline $\begin{array}{c}\text { Meta } \\
10\end{array}$ & $\begin{array}{l}\text { (Justiça Federal) Designar 10\% a mais de audiências de conci- } \\
\text { liação do que as designadas no ano anterior (2011). }\end{array}$ & $80 \%$ \\
\hline $\begin{array}{c}\text { Meta } \\
11\end{array}$ & $\begin{array}{l}\text { (Justiça Federal) Implantar gestão por processos de trabalho } \\
\text { (gerenciamento de rotinas) em } 50 \% \text { das turmas recursais. }\end{array}$ & $80 \%$ \\
\hline $\begin{array}{c}\text { Meta } \\
12\end{array}$ & $\begin{array}{l}\text { Realizar pesquisa sobre a qualidade da prestação dos serviços } \\
\text { e satisfação do cidadão nos tribunais eleitorais. }\end{array}$ & $100 \%$ \\
\hline $\begin{array}{c}\text { Meta } \\
13\end{array}$ & $\begin{array}{l}\text { (Justiça Eleitoral) Implantar pelo menos uma iniciativa de promo- } \\
\text { ção da cidadania voltada para jovens. }\end{array}$ & $100 \%$ \\
\hline $\begin{array}{l}\text { Meta } \\
14\end{array}$ & $\begin{array}{l}\text { (Justiça do Trabalho) Estabelecer o Programa de Controle Médi- } \\
\text { co de Saúde Ocupacional (PCMSO) e Programa de Prevenção } \\
\text { de Riscos Ambientais (PPRA) em pelo menos } 60 \% \text { das unidades } \\
\text { judiciárias e administrativas. }\end{array}$ & $32 \%$ \\
\hline $\begin{array}{l}\text { Meta } \\
15\end{array}$ & $\begin{array}{l}\text { (Justiça do Trabalho) Capacitar, com carga horária mínima de } 20 \\
\text { horas, } 20 \% \text { dos magistrados e } 20 \% \text { dos servidores na utilização } \\
\text { do Processo Judicial Eletrônico (PJe) e em gestão estratégica. }\end{array}$ & $50 \%$ \\
\hline $\begin{array}{c}\text { Meta } \\
16\end{array}$ & $\begin{array}{l}\text { (Justiça do Trabalho) Implantar o Processo Judicial Eletrônico (PJe) } \\
\text { em, pelo menos, } 10 \% \text { das Varas de Trabalho de cada tribunal. }\end{array}$ & $95,83 \%$ \\
\hline $\begin{array}{c}\text { Meta } \\
17\end{array}$ & $\begin{array}{l}\text { (Justiça do Trabalho) Aumentar em 10\% o quantitativo de execu- } \\
\text { ções encerradas em relação a } 2011 .\end{array}$ & $41,66 \%$ \\
\hline $\begin{array}{c}\text { Meta } \\
18\end{array}$ & $\begin{array}{l}\text { (Justiça do Trabalho) Executar, até setembro de 2012, pelo me- } \\
\text { nos } 60 \% \text { do orçamento anual disponível, excluídas as despesas } \\
\text { de pessoal. }\end{array}$ & $48 \%$ \\
\hline $\begin{array}{c}\text { Meta } \\
19\end{array}$ & $\begin{array}{l}\text { Desenvolver normas e políticas de gestão documental para a } \\
\text { Justiça Militar da União. }\end{array}$ & $0 \%$ \\
\hline
\end{tabular}

Fonte: elaborada pela autora com base nos relatórios fornecidos pelo CNJ. 
Tabela 5 - Metas nacionais do CNJ referentes ao ano de 2013

\begin{tabular}{|c|c|c|}
\hline Meta & Descrição & $\begin{array}{l}\text { Total de } \\
\text { cumpri- } \\
\text { mento }\end{array}$ \\
\hline Meta 1 & $\begin{array}{l}\text { Julgar mais processos de conhecimento do que os distribuídos } \\
\text { em } 2013 \text {. }\end{array}$ & $91,34 \%$ \\
\hline Meta 2 & $\begin{array}{l}\text { Julgar, até } 31 \text { de dezembro de } 2013 \text {, pelo menos } 80 \% \text { dos pro- } \\
\text { cessos distribuídos em } 2008 \text { no STJ. }\end{array}$ & $123,92 \%$ \\
\hline Meta 3 & $\begin{array}{l}\text { (Justiça Militar Estadual) Julgar 90\% dos recursos cíveis e crimi- } \\
\text { nais em até } 120 \text { dias. }\end{array}$ & $108,27 \%$ \\
\hline Meta 4 & $\begin{array}{l}\text { (Justiça Militar Estadual) Implantar o processo judicial eletrônico } \\
\text { em } 25 \% \text { das unidades judiciárias. }\end{array}$ & $0 \%$ \\
\hline Meta 5 & $\begin{array}{l}\text { (Justiça Federal) Designar audiências e realizar demais ativida- } \\
\text { des de conciliação adequadas à solução de conflitos em número } \\
\text { maior do que o ano de } 2012 \text {. }\end{array}$ & $78,43 \%$ \\
\hline Meta 6 & $\begin{array}{l}\text { (Justiça Federal) Implementar gestão por processos de trabalho } \\
\text { (gerenciamento de rotinas) em } 100 \% \text { das turmas recursais. }\end{array}$ & $100 \%$ \\
\hline Meta 7 & $\begin{array}{l}\text { (Justiça Eleitoral) Modelar pelo menos cinco processos de traba- } \\
\text { Iho das unidades judiciárias de } 1^{\circ} \text { Grau da Justiça Eleitoral. }\end{array}$ & $44 \%$ \\
\hline Meta 8 & $\begin{array}{l}\text { (Justiça Eleitoral). Implantar e divulgar a "Carta de Serviços" do } \\
2^{\circ} \text { Grau da Justiça Eleitoral. }\end{array}$ & $97,53 \%$ \\
\hline Meta 9 & $\begin{array}{l}\text { (Justiça do Trabalho) Implementar o Programa de Controle Médi- } \\
\text { co de Saúde Ocupacional (PCMSO) e o Programa de Prevenção } \\
\text { de Riscos Ambientais (PPRA) em, pelo menos, } 65 \% \text { das unida- } \\
\text { des judiciárias e administrativas. }\end{array}$ & $31,10 \%$ \\
\hline Meta 10 & $\begin{array}{l}\text { (Justiça do Trabalho) Realizar adequação ergonômica em } 20 \% \\
\text { das unidades judiciárias de } 1^{\circ} \text { e } 2^{\circ} \text { Graus. }\end{array}$ & $89,02 \%$ \\
\hline Meta 11 & $\begin{array}{l}\text { (Justiça do Trabalho) Capacitar, com duração mínima de } 20 \text { ho- } \\
\text { ras, } 50 \% \text { dos magistrados e } 50 \% \text { dos servidores na utilização do } \\
\text { Processo Judicial Eletrônico (PJe) e em gestão estratégica. }\end{array}$ & $119,20 \%$ \\
\hline Meta 12 & $\begin{array}{l}\text { (Justiça do Trabalho) Implantar o Processo Judicial Eletrônico } \\
\text { (PJe) em pelo menos 40\% das Varas do Trabalho de cada tribunal. }\end{array}$ & $150,16 \%$ \\
\hline Meta 13 & $\begin{array}{l}\text { (Justiça do Trabalho) Aumentar em 15\% o quantitativo de execu- } \\
\text { ções encerradas em relação a } 2011 .\end{array}$ & $80,23 \%$ \\
\hline Meta 14 & $\begin{array}{l}\text { (Justiça do Trabalho) Executar, até setembro de 2013, pelo menos 65\% } \\
\text { do orçamento anual disponível, excluídas as despesas com pessoal. }\end{array}$ & $88,39 \%$ \\
\hline Meta 15 & $\begin{array}{l}\text { (Justiça Militar da União) Desenvolver versão teste de sistema } \\
\text { de gestão eletrônica administrativa e judicial. }\end{array}$ & $25 \%$ \\
\hline Meta 16 & Fortalecer a unidade de controle interno no Tribunal. & $84,38 \%$ \\
\hline Meta 17 & $\begin{array}{l}\text { Desenvolver, nacionalmente, sistemas efetivos de licitação e } \\
\text { contratos. }\end{array}$ & $83,85 \%$ \\
\hline Meta 18 & $\begin{array}{l}\text { Identificar e julgar, até } 31 \text { de dezembro de } 2013 \text {, as ações de impro- } \\
\text { bidade administrativa e ações penais relacionadas a crimes contra } \\
\text { a administração pública, distribuídas até } 31 \text { de dezembro de } 2011 \text {. }\end{array}$ & $55,68 \%$ \\
\hline Meta 19 & $\begin{array}{l}\text { (Justiça Federal, Estadual e Eleitoral) Realização de parcerias } \\
\text { entre o CNJ, os TJs, os TRFs, Os TREs e os Tribunas de Contas, } \\
\text { para aperfeiçoamento e alimentação do Cadastro Nacional de } \\
\text { Condenações Cíveis por ato de improbidade administrativa. }\end{array}$ & - \\
\hline
\end{tabular}


Tabela 6 - Metas nacionais do CNJ referentes ao ano de 2014

\begin{tabular}{|c|c|c|}
\hline Meta & Descrição & $\begin{array}{c}\text { Total de } \\
\text { cumprimento }\end{array}$ \\
\hline Meta 1 & $\begin{array}{l}\text { Julgar mais processos de conhecimento do que os distribuídos } \\
\text { em } 2014 \text {. }\end{array}$ & $91,49 \%$ \\
\hline Meta 2 & $\begin{array}{l}\text { Julgar, até } 31 \text { de dezembro de } 2014 \text {, pelo menos } 100 \% \text { dos } \\
\text { processos distribuídos até } 31 \text { de dezembro de } 2008 \text { e } 80 \% \text { dos } \\
\text { distribuídos em } 2009 \text { no STJ. }\end{array}$ & $96,96 \%$ \\
\hline Meta 3 & $\begin{array}{l}\text { (Justiça Estadual e do Trabalho) Estabelecer e aplicar parâme- } \\
\text { tros objetivos de distribuição da força de trabalho, vinculados à } \\
\text { demanda de processos, com garantia de estrutura mínima das } \\
\text { unidades da área fim. }\end{array}$ & $33,33 \%$ \\
\hline Meta 4 & $\begin{array}{l}\text { (Tribunais Superiores e Justiça Federal) Identificar e julgar, até } \\
31 \text { de dezembro de } 2014 \text {, as ações de improbidade administra- } \\
\text { tiva e as ações penais relacionadas a crimes contra a adminis- } \\
\text { tração pública. }\end{array}$ & $83,43 \%$ \\
\hline Meta 5 & $\begin{array}{l}\text { (Justiça do Trabalho e Federal) Reduzir o congestionamento, } \\
\text { em relação à taxa média de } 2013 \text { e } 2012 \text {, na fase de cumpri- } \\
\text { mento de sentença e de execução. }\end{array}$ & $86,02 \%$ \\
\hline Meta 6 & $\begin{array}{l}\text { Identificar e julgar, até } 31 \text { de dezembro de } 2014 \text {, as ações cole- } \\
\text { tivas distribuídas até } 31 \text { de dezembro de } 2011 \text {, no } 1^{\circ} \text { Grau e no } \\
\text { TST, e até } 31 \text { de dezembro de } 2012 \text {, no } 2^{\circ} \text { Grau. }\end{array}$ & $100 \%$ \\
\hline
\end{tabular}

Tabela 7 - Metas nacionais do CNJ referentes ao ano de 2015

\begin{tabular}{clc}
\hline Meta & \multicolumn{1}{c}{ Descrição } & $\begin{array}{c}\text { Total de } \\
\text { cumprimento }\end{array}$ \\
\hline Meta 1 & $\begin{array}{l}\text { Julgar mais processos de conhecimento do que os distribuídos } \\
\text { em 2015. }\end{array}$ & $41,11 \%$ \\
\hline Meta 2 & $\begin{array}{l}\text { (Todos os tribunas) Identificar e julgar, até 31 de dezembro de } \\
\text { 2016, determinado percentual de processos antigos, de diver- } \\
\text { sos períodos de tramitação. }\end{array}$ & $93,31 \%$ \\
\hline Meta 3 & $\begin{array}{l}\text { (Todos os tribunais) Aumentar o percentual de casos solucio- } \\
\text { nados por conciliação em relação ao ano anterior e impulsionar } \\
\text { os trabalhos dos CEJUSCs. }\end{array}$ & $21,88 \%$ \\
\hline Meta 4 & $\begin{array}{l}\text { (Todos os tribunais) Identificar e julgar as ações de improbi- } \\
\text { dade administrativa e as ações penais relacionadas a crimes } \\
\text { contra a administração pública. }\end{array}$ & $89,62 \%$ \\
\hline Meta 5 & $\begin{array}{l}\text { (Justiça do Trabalho e Federal) Baixar em 2015 quantidade } \\
\text { maior de processos de execução do que o total de casos novos } \\
\text { de execução no ano corrente. }\end{array}$ & $44,83 \%$ \\
\hline Meta 6 & $\begin{array}{l}\text { ldentificar e julgar, até 31 de dezembro de 2015, as ações coletivas } \\
\text { distribuídas até 31 de dezembro de 2012, no 1 }{ }^{\circ} \text { Grau e no TST. }\end{array}$ & $97,65 \%$ \\
\hline Meta 7 & $\begin{array}{l}\text { (Justiça Estadual e do Trabalho) Priorizar o julgamento dos } \\
\text { processos dos maiores litigantes e dos recursos repetitivos. }\end{array}$ & $49,06 \%$ \\
\hline \hline
\end{tabular}

Fonte: elaborada pela autora com base nos relatórios fornecidos pelo CNJ. 
Tabela 8 - Metas nacionais do CNJ referentes ao ano de 2016

\begin{tabular}{|c|c|c|}
\hline Meta & Descrição & $\begin{array}{c}\text { Total de } \\
\text { cumprimento }\end{array}$ \\
\hline Meta 1 & $\begin{array}{l}\text { Julgar mais processos de conhecimento do que os distribuídos } \\
\text { em } 2016 \text {. }\end{array}$ & $30 \%$ \\
\hline Meta 2 & $\begin{array}{l}\text { (Todos os tribunais) Identificar e julgar, até } 31 \text { de dezembro de } \\
2016, \text { determinado percentual de processos antigos, de diversos } \\
\text { períodos de tramitação. }\end{array}$ & $94,06 \%$ \\
\hline Meta 3 & $\begin{array}{l}\text { (Todos os tribunais) Aumentar o percentual de casos soluciona- } \\
\text { dos por conciliação em relação ao ano anterior e impulsionar os } \\
\text { trabalhos dos CEJUSCs. }\end{array}$ & $42,86 \%$ \\
\hline Meta 4 & $\begin{array}{l}\text { (Todos os tribunais) Identificar e julgar as ações de improbidade } \\
\text { administrativa e as ações penais relacionadas a crimes contra a } \\
\text { administração pública. }\end{array}$ & $93,93 \%$ \\
\hline Meta 5 & $\begin{array}{l}\text { (Todos os tribunais) Baixar em } 2016 \text { quantidade maior de pro- } \\
\text { cessos de execução do que o total de casos novos de execução } \\
\text { no ano corrente. }\end{array}$ & $46,43 \%$ \\
\hline Meta 6 & $\begin{array}{l}\text { (Todos os tribunais) Identificar e julgar, até } 31 \text { de dezembro de } \\
2016 \text {, determinado percentual de ações coletivas e recursos } \\
\text { oriundos de ações coletivas distribuídos em diversos períodos } \\
\text { de tramitação. }\end{array}$ & $98,45 \%$ \\
\hline Meta 7 & $\begin{array}{l}\text { (Justiça Estadual e do Trabalho) Priorizar o julgamento dos pro- } \\
\text { cessos dos maiores litigantes e dos recursos repetitivos. }\end{array}$ & $52,94 \%$ \\
\hline Meta 8 & $\begin{array}{l}\text { Implementar projeto com equipe capacitada para oferecer prá- } \\
\text { ticas de Justiça Restaurativa, implantando ou qualificando pelo } \\
\text { menos uma unidade para esse fim, até } 31 \text { de dezembro de } 2016 \text {. }\end{array}$ & $78,31 \%$ \\
\hline
\end{tabular}

\section{CONSIDERAÇÕES FINAIS}

O planejamento estratégico no âmbito judicial, por meio de metas e indicadores de desempenho, está contribuindo para o desenvolvimento dos tribunais pátrios e para a reformulação das práticas cotidianas da Justiça brasileira. Ademais, a mensuração estatística utilizada pelo Poder Judiciário vem possibilitando a formulação de metas e objetivos mais adequados à prática das Cortes, fornecendo um melhor embasamento para a tomada de decisões no que diz respeito ao planejamento estratégico nacional, além da expansão da reflexão crítica acerca da prestação de seus serviços.

A evolução dos relatórios anuais do Conselho Nacional de Justiça vem, portanto, ratificar a importância de se pensar sobre a inserção de processos da iniciativa privada tanto no setor público em geral como na seara judicial. Logo, pode-se inferir que a inserção das metas nacionais estipuladas pelo CNJ trouxe como um dos seus principais efeitos o aumento da produtividade dos tribunais. Constata-se que a adoção de métodos e rotinas de gerenciamento nessas Cortes resultou na 
otimização de suas funções. No mais, a modernização do aparelhamento existente, como, por exemplo, a implementação de sistemas informatizados, trouxe como consequência uma maior celeridade na tramitação e deslinde dos processos.

Não obstante a Justiça ainda ser taxada de morosa pela sociedade, resta evidente que se encontra muito mais célere do que antes da adoção de tais práticas. Em suma, a adoção de um planejamento estratégico no âmbito dos Tribunais pátrios foi extremamente benéfica, na medida em que passou a ter como corolário uma gestão focada na eficiência e eficácia da jurisdição.

Por fim, cumpre destacar que se evitou o exame pormenorizado das metas constantes das tabelas expostas eis que seria por demasiado extenso - o que extrapolaria o escopo deste trabalho. Optou-se, então, por fazer uma análise global das metas do $\mathrm{CNJ}$, de forma a sugerir uma resposta à pergunta-problema do estudo. A metodologia, portanto, é limitada, centrada na pesquisa bibliográfica.

Reconhecendo as limitações da presente pesquisa, tanto em relação ao tipo de estudo, quanto à abordagem teórica, levanta-se um assunto atual percebido pela administração pública, porém pouco desbravado na seara acadêmica. Sendo assim, propõe-se que pesquisas futuras abordem com mais profundidade tanto o processo de implementação do planejamento estratégico no Poder Judiciário como seus resultados.

\section{REFERÊNCIAS}

Associação Brasileira de Normas Técnicas (2008). Norma Brasileira NBR ISO 9001. (2. ed. rev.).

Abrucio, F. L. (2005). Reforma do Estado no federalismo brasileiro: a situação das administrações públicas estaduais. Revista de Administração Pública, 39(2), 401-420.

Abrucio, F. L., \& Sano, H. (2008). Promessas e resultados da nova gestão pública no Brasil: O caso das Organizações Sociais de Saúde em São Paulo. Revista de Administração de Empresas, 48(3), 64-80.

Allison, G. (2002). Public and private management: Are they fundamentally alike in all unimportant respects? In J. M. Shafritz, A. C. Hyde, \& S. J. Parkes (Eds.), Classics of Public Administration. Thomson-Wadsworth.

Ansoff, I. (1969). Business strategy. England: Penguin Books.

Appleby, P. (2002). Government is different. In. J. M. Shafritz, A. C. Hyde, \& S. J. Parkes. Classics of Public Administration. Thomson-Wadsworth.

Barzelay, M. (2001). The new public management: Improving research and policy 
dialogue. University of California Press/Russel Sage Foundation.

Belchior, M. (1999). A aplicação do Planejamento Estratégico Situacional em governos locais: Possibilidades e limites - os casos de Santo André e São José dos Campos. (Dissertação de Mestrado). Escola de Administração de Empresas de São Paulo, Fundação Getulio Vargas, São Paulo.

Bordasch, R. W. da S. (2009). Gestão cartorária: controle e melhoria para a razoável duração dos processos. Coleção Administração Judiciária, IV. Departamento de Artes Gráficas do TJRS.

Brasil (1988). Constituição Federal. Brasília: Senado Federal. Recuperado de http://www.planalto.gov.br/ccivil_03/constituicao/constituicao.htm

Bresser-Pereira, L. C. (1997). Estratégia e estrutura para um novo Estado. Revista de Economia Política, 17(3).

Bresser-Pereira, L. C. (2000). A reforma gerencial do Estado de 1995. Revista de Administração Pública, 34(4), 55-72.

Campos, A. M. (1990). Accountability: Quando poderemos traduzi-la para o Português? Revista de Administração Pública, 24(2), 30-50.

Campos, C. C. (2010). Editorial. Cadernos FGV Projetos, ano 5 (12), 6-7.

Cavalcanti, B. S. (2005). O gerente equalizador: Estratégias de gestão no setor público. Rio de Janeiro: FGV.

Conselho Nacional de Justiça (2009a). Dispõe sobre o Planejamento e a Gestão Estratégica no âmbito do Poder Judiciário e dá outras providências. ResoIução $n^{\circ} 70$, de 18 de março de 2009. Recuperado de http://www.cnj.jus.br/ gestao-e-planejamento/gestao-e-planejamento-do-judiciario/resolucao-n-70

Conselho Nacional de Justiça (2009b). Indicadores do Planejamento Estratégico do Poder Judiciário. Recuperado de http://www.cnj.jus.br/programasde-a-a-z/eficiencia-modernizacao-e-transparencia/pj-justica-em-numeros/2013-01-04-19-13-21, 28-12-2017

Conselho Nacional de Justiça (2009c). Justiça em Números: Indicadores do Poder Judiciário. Recuperado de http://www.cnj.jus.br/programas-de-a-a-z/ eficiencia-modernizacao-e-transparencia/pj-justica-em-numeros

Costin, C. (2010). Administração Pública. Rio de Janeiro: Elsevier.

Cunha, A. (2010). A busca de maior vitalidade da gestão nas organizações do Poder Judiciário. Cadernos FGV Projetos, ano 5, 12, 45-51.

Darós, V. (2009). Planejamento Estratégico do TRF da $4^{a}$ Região. Caderno de Administração da Justiça: Planejamento Estratégico. 
Deolindo, V. (2010). Planejamento Estratégico em Comarca do Poder Judiciário. (Dissertação de Mestrado). Escola de Direito, Fundação Getulio Vargas, Rio de Janeiro.

Diefenbach, T. (2009). New public management in public sector organizations: the dark sides of managerialistic 'enlightenment'. Public Administration, 87(4), 892-909.

Dror, Y. (1999). A capacidade para governar. Informe ao Clube de Roma. Edições FUNDAP.

Drucker, P. (1984). Introdução à administração. São Paulo: Futura.

Dunlop, J. T. (1979). Public Management. Unpublished paper. In: J. M. Shafritz, A. C. Hyde, \& S. J. Parkes. Classics of Public Administration. (5. ed.). Thomson-Wadsworth.

Fleury, N. (2005). A resposta da gestão estratégica às exigências de efetividade, eficácia e eficiência no Poder Judiciário. In: A. Cunha, \& P. Motta. A reforma do Poder Judiciário no estado do Rio de Janeiro. Rio de Janeiro: Fundação Getulio Vargas, 25-36.

Frederickson, H. G. (1989). Changing epochs of Public Administration. Public Administration Review, 49(2), (special issue).

Grangeia, M. A. D. (2007). Modelagem organizacional, gestão administrativa e de procedimentos judiciais de Cartório Cível. (Dissertação de Mestrado). Escola de Direito, Fundação Getulio Vargas, Porto Velho.

Herold, D. (1972). Long-range planning and organizational performance: A CrossValuation Study. Academy of Management Journal, 15(1).

Jobim, N. (2004). Discurso de posse na presidência do Supremo Tribunal Federal. 3 jun. 2004. Recuperado de http://www.stf.jus.br/portal/cms/verNoticiaDetalhe. asp?idConteudo $=100094 \&$ sigServico $=$ noticiaArtigoDiscurso\&caixaBusca $=\mathrm{N}$

Jobim, N. (2005). Judiciário: construindo um novo modelo. In: A. Cunha, \& P. Motta. A reforma do Poder Judiciário no estado do Rio de Janeiro. Rio de Janeiro: Fundação Getulio Vargas.

Kern, R. A. (2011). Perspectivas sobre o planejamento estratégico no âmbito da Administração da Justiça. Revista de Doutrina da $4^{a}$ Região, 41. Recuperado de http://www.revistadoutrina.trf4.jus.br/artigos/edicao041/ricardo_kern. html

Koury, S. C. (2010). Planejamento estratégico do poder judiciário: o papel das escolas judiciais. Revista do Tribunal Regional do Trabalho da $9^{a}$ Região, 35(64). Recuperado de http://www.enamat.gov.br/ 
Leme, E. (2010). O juiz como gestor. Poder Judiciário e Gestão Eficiente. Cadernos FGV Projetos, 12, 20-23.

Manzini, R. (2010). O desdobramento da estratégia através do Balanced Scoredcard: lições da experiência no Poder Judiciário Nacional. Poder Judiciário e Gestão Eficiente. Cadernos FGV Projetos, 12, 53-62.

Marcovitch, J., \& Vasconcellos, E. (1977). Técnicas de planejamento estratégico para instituições de pesquisa e desenvolvimento. Revista de Administração, 12(1), 61-78.

Marcovitch, J., \& Radosevich, R. (1978). Planejamento estratégico nas organizações estruturadas por projeto. Revista de Administração, 13(2), 24-39.

Marin, J.-C. (2012). The impact of strategic planning and the balanced scorecard methodology on middle managers' performance in the public sector. International Journal of Business \& Social Science, 3(1).

Mendes, G. (2010). Entrevista com o Ministro Gilmar Mendes. Poder Judiciário e Gestão Eficiente. Cadernos FGV Projetos, ano 5, 12, 8-19.

Milward, H. B., \& Provan, K. G. (2000). Governing the Hollow State. Journal of Public Administration Research and Theory, 193-314.

Mintzberg, H. (1994). The fall and rise of strategic planning. Harvard Business Review, 72(1), 103-108.

Mintzberg, H., Ahlstrand, B., \& Lampel, J. (2000). Safári de estratégia: um roteiro pela selva do planejamento estratégico. Trad. Nivaldo Montingelli Jr. Porto Alegre: Bookman.

Motta, P. R. (2012). Planejamento das organizações públicas. Apostila do Mestrado Acadêmico em Administração Pública.

Neustadt, R. E. (1979). American Presidents and Corporate Executives. Panel on presidential management of the National Academy of Public Administration, Washington, D. C.

Nogueira, J. M. M. (2010). A gestão do Poder Judiciário: Uma análise do sistema de mensuração de desempenho do Judiciário brasileiro. (Dissertação de Mestrado). Escola de Administração de Empresas de São Paulo, São Paulo.

Osborne, D.; \& Gaebler, T. (1996). Reinventing government: Introduction. In: J. M. Shafritz, \& J. S. Ott. Classics of Organization Theory, Harcourt Brace.

Pacheco, R. S. (2004). Contratualização de resultados no setor público: a experiência brasileira e o debate internacional. Anais do IX Congreso Internacional del CLAD sobre la Reforma del Estado y de la Administración Pública, Madrid, España. 
Paula, M. E. de. (2006). Poder Judiciário: Crise e reforma. (Dissertação de Mestrado). Universidade Federal do Rio Grande do Sul, Porto Alegre. Recuperado de http://www.lume.ufrgs.br/bitstream/handle/10183/13181/000598349.pdf

Peci, A., Pieranti, O. P., \& Rodrigues, S. (2008). Governança e New Public Management: Convergências e contradições no contexto brasileiro. Revista Organizações \& Sociedade, 15(46), 39-55.

Peters, B. G.; \& Pierre, J. (1998). Governance without government: rethinking Public Administration. Journal of Public Administration Research and Theory, 8, 223-244.

Sadek, M. T. A. (2004a). Poder Judiciário: Perspectivas de reforma. Opinião Pública, 10(1), 1-62.

Sadek, M. T. A. (2004b). Judiciário: Mudanças e reformas. Estudos Avançados, 18(51), 79-101.

Shick, A. (1996). The Spirit of Reform: Managing the New Zealand State Sector in a Time of Change. Wellington, New Zealand: State Services Comission and the Treasury. Recuperado de www.sse.govt.nz

Stumpf, J. da C. (2009). Poder Judiciário: Morosidade e inovação. Porto Alegre: Tribunal de Justiça do Estado do Rio Grande do Sul, Departamento de Artes Gráficas. Coleção Administração Judiciária, 2.

Suannes, A. (2007). O processo judicial e a teoria do caos. Revista da Ajuris, Porto Alegre, 105, 9-37.

Taylor, B. (1975). Strategies for planning: Long Range Planning, Elmsford, 27-40.

Tesheiner, J. M. R. (2001). Reforma do Judiciário. Revista Jurídica, 286, 45-48. 